\title{
The study results of environmental design engineers' professional activity psychological readiness
}

\author{
Olena Khokhlina ${ }^{1}$, Liubov Pomytkina ${ }^{1,}{ }^{*}$, Lada Yakovytska $^{1}$, Olena Ichanska $^{1}$, and Denys \\ Khokhlin ${ }^{2}$ \\ ${ }^{1}$ National Aviation University, ave. Liubomyra Huzara 1, 03058, Kyiv, Ukraine \\ ${ }^{2}$ Kyiv National University of Construction and Architecture, ave. Povitroflotskyy, 31, 03037, Kyiv, \\ Ukraine
}

\begin{abstract}
The article presents the results of theoretical and empirical research of the design engineers' (civil engineering) professional activity psychological readiness problem, which was carried out in the general and special abilities' theory context, the need to take into account general and individual typological mental development. The subject of study was intellectual readiness for work, as a system of mental activity qualities generalization, awareness, independence, resilience, which are necessary for solving work tasks, and individual style of work - its formation (certainty), compliance with the reference method of work tasks and executive, in connection with the labor activity efficiency - quality and time costs. It was found that these pgsychological readiness components are interrelated, and the oranizing factor in their unity (as well as specific elements and indicators of manifestation) is the generalization of mental activity, which provides the subject's ability to determine and use the optimal way to solve work problems. The conclusion about the need for professionals to develop psychological readiness to work in such a structure is based on the results of empirical research.
\end{abstract}

\section{Introduction}

Ensuring the professional activity effectiveness and the success of it's preparation involves the study of problem's psychological aspects, and above all the definition of important labor subject specificities for the labor tasks performance. This requires study research of the specificities, that make up the professional activity psychological readiness content. We proceeded from the fact, that such readiness is an integrative personal formation, based on the activities positive attitude formation, necessary to perform the features of the psyche cognitive and emotional-volitional spheres, personal characteristics abilities, character, temper. That is, such readiness is considered as long-term (as opposed to temporary, situational) readiness of all psyche spheres for activity.

Considering the results of the pilot study (Khokhlina et al.) [1], at the stage of the study in-depth study was subject to psychological, namely intellectual, readiness for work and

\footnotetext{
* Corresponding author: Lyubvit@ukr.net
} 
individual style of activity in connection with the work tasks effectiveness. Based on the theory of activity (Leontiev, Lomov, Khokhlina, Synov etc.) [2], the theory of general and special abilities (Kostyuk, Krutetsky, Levitov, Laytes, Rubinstein etc.), their essence and relationship in different types of professional activity (Rubinshtein), the difference between them (even the disproportion) is observed when special talents (including features of the nervous system, structure and functioning of analyzers, etc.) and special equipment of the employee play a special role in the special ability. In our theoretical model, general abilities are represented by intellectual readiness, and special ones by individual style of activity; thus the requirement to take into account the general and individual-typological in the subject's mental development of labor is realized. And the more complex the level of work tasks are to be solved by a professional, the more intellectual readiness for activity should be formed by him. When the activity places the subject more specific requirements to perform actions, to the nervous and sensory spheres, requires action in extreme conditions, conditions of increased tension and responsibility, the importance and role of activity individual style and its formation increases.

Intellectual readiness for activity, as the of the subject's mental sphere readiness for its implementation, has a special role in achieving indicators of its effectiveness in terms of increased labor intellectualization in all its spheres (Herrera, \& Barrientos; Micallef, Huet, \& Kayyali; Nagovitsyn et al .; Petrova , \& Kozlova etc.) [3-6]. The formation of such readiness, in accordance with the subject-activity concept, is a necessary condition for achieving professional skills, the possibility of supersituational activity, creativity, and thus - personal development (Tkachenko, Asmolov, Petrovskyi, etc.).

We define the essence of individual style of activity in the context of the human adaptation problem with its individual-typological, natural, and first of all temperamental specificities of activity, ensuring its assimilation and execution efficiency (Klymov; Merlin; Khokhlina et al .; Luzik, Akmaldinova, \& Tereminko; Pakhmutova et al .; Ponomarenko, Krylov, \& Somova; Tolochek; Topuzov, Malykhin, \& Yarmolchuk) [1, 712]. Temper is based on the nervous system specificities, which, depending on the profession, have different requirements. And the more the activity is associated with extreme conditions, the need for rapid decision-making, etc., the more the subject's nervous processes require strength, movability and poise. This takes into account, that the weakness and inertia of the nervous system are not negative properties; "weak" and "inert" type, on the one hand, and "strong" and "movable", on the other, are types that characterize different ways of balancing the body with the environment, rather than different degrees of nervous system perfection (Teplov). One of the ways to adapt the activity temperamental man's characteristics is the person's individual style formation of activity.

Goal - covering the results of theoretical and empirical study of psychological readiness for design engineers' professional work.

The hypothes of the study is that the design engineers' professional activities effectiveness is associated with the level of their psychological work readiness formation mental qualities and individual style of work.

\section{Methods}

Theoretical and empirical methods of psychological research are used, including observation of the process and work results, survey, expert evaluation method, studying documentation method, experiment using a specially designed work tasks system to study mental qualities, individual style and efficiency, testing with the standardized psychological methods use, namely: modified to the objectives of the research method of studying semantic generalizations (Nosatov), tapping test "Determination of the nervous system specificities by psychomotor parameters" (Ilin); questionnaire "Predominant type of 
temperament" (Bielov); methodology "Feeling, activity and mood"; self-assessment questionnaire of own type of ISW and a method of generalization of independent characteristics to determine the nervous system specificities (Akimova, \& Kozlova); as well as procedures for qualitative and quantitative processing. The research covered 32 design engineers (civil engineering).

\section{Results}

At the empirical stage of the study of psychological readiness for activity, intellectual readiness, individual style of activity and its effectiveness were studied. We proceeded from the following understanding of the studied phenomena. Intellectual readiness is the mental activity (mind, thinking) qualities system formation (Kalmykova, Khokhlina, Levitov, Leites, Menchynskaia, Raiev, etc.), on which depends the ability to effectively solve work problems. Such qualities are generated, developed and manifested in the process of work. The mental qualities formation, in turn, is the result of the thinking development, the essence of which is in the preliminary determination of the activity mode on the basis of the ability to generalize (Slavskaia). The generalization of thinking, as a focus on the selection of essential in the material, which in practice ensures the effective achievement of the goal in changing conditions and the ability to determine the optimal way of working - is the key mental formation of intellectual readiness. Among other mental qualities in the intellectual readiness system for activity were determined awareness, independence and resilience. Awareness of mental activity is seen as the ability to understand and verbalize, ie verbally reproduce the conscious. The subject of awareness is one's own mental activity in the solving a labor task process and, first of all, a certain way of its fulfillment. Independence of mental activity - is the ability to solve a problem in the process of performing a work task without assistance, and resilience- appropriate emphasis on the selected by the subject essential for solving the problem features during the work task. Resilience creates the possibility of relatively long-term mental activity in working conditions and bringing the work task to completion.

Individual style of work (ISW) is considered as a stable system of working ways, due to individual typological specificities of a person consistently characterizes it in typical conditions, provides the best (effective) performance of work tasks and does not cause negative feelings (Klymov; Merlin; Khokhlina et al; Tolochek, etc.) $[1,7,11]$.

Thus, the intellectual readiness for activity (formation of qualities of mental activity generalization, awareness, independence and resilience) was in-depth study subject; individual style of activity - the level of compliance with the reference method, the formation (or certainty) of the style and its type (preparatory or executive); work tasks efficiency - quality (including correctness and completeness) and time costs. The obtained data on the manifestation of certain phenomena were subject to correlation analysis, the most significant results of which are presented in the matrix of intercorrelations (table 1). 
Table 1. Intercorrelations matrix of intellectual readiness for activity, its individual style and efficiency.

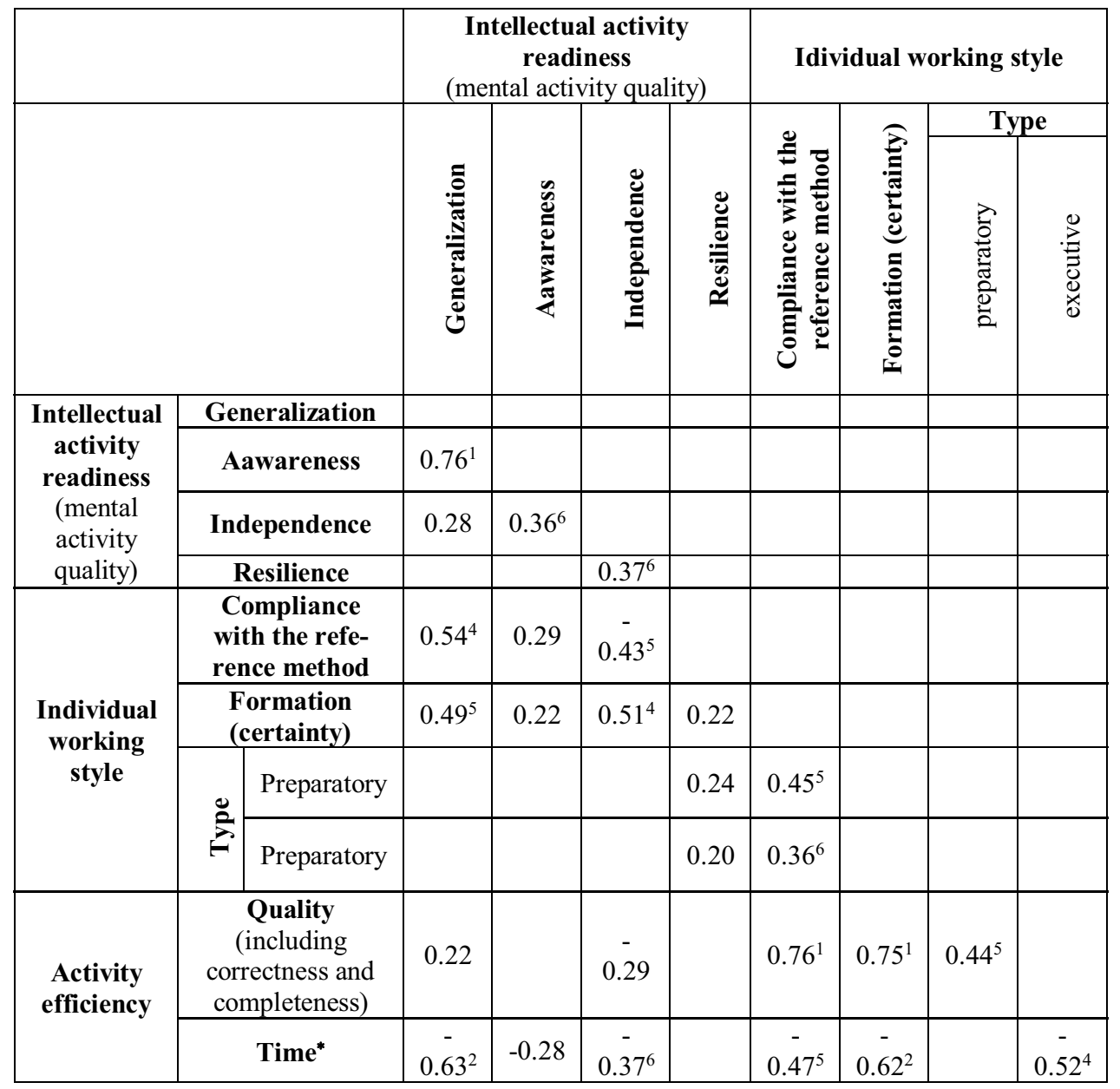

$1 \rho<0.001 ; 2 \rho<0.01 ; 3 \rho<0.02 ; 4 \rho<0.05 ; 5 \rho<0.10 ; 6 \rho<0.20$.

* Quantitative data of the task execution time are inverse.

The matrix of intercorrelations between the studied phenomena shows the following.

1. Between the quality indicator efficiency (including correctness, completeness) and time costs, on the one hand, and intellectual readiness to perform work tasks are slightly affected by the generalization of mental activity, and vice versa $\left(\rho^{\mathrm{s}}=0.22\right)$; manifestation of its independence slightly reduces the quality of work; improving the quality is facilitated by the additional appeal of the subject with a help of information sources or advice from colleagues, etc. $\left(\rho^{\mathrm{s}}=-0.29\right)$.

2. There is a certain increase in the relationship between the efficiency of time indicators and the components of intellectual readiness. Thus, the ability of the mind to generalize $\left(\rho^{s}=-0.632\right)$ has the greatest effect on the speed of tasks. Relationship, but of the low level $\left(\rho^{\mathrm{s}}=-0.376 ;-0.28\right)$ : was found between the time of work tasks and independence and mental activity awareness. That is, conscious, independent problem solving has a positive effect on its speed. 
3. Acting efficiency is most closely related to ISW. Thus, a clear inverse relationship was found between the activity efficiency in terms of time and ISW (in accordance with the reference method and the formation) $\left(\rho^{\mathrm{s}}=-0.475 ;-0.622\right)$. That is, the more formed (defined) the ISW is and the more it corresponds to the reference method, the less time is spent on solving the work task, and vice versa. However, it should be noted that the same level of relationship was observed between the tasks time and the attribution of the subject's ISW only to the executive type $\left(\rho^{\mathrm{s}}=-0.524\right)$; no significant correlation of the time performance indicator with reference to the preparatory type was found. It is established that the type of ISW (preparatory or executive) has almost no effect on the labor efficiency indicators achievement.

4. The work efficiency in terms of quality (including accuracy, completeness of performance) with ISW is associated with a high and expressive level. Thus, the work tasks performance is better done by the subject, who has already formed an individual style and whose method is close to the reference one (respectively, $\rho^{s}=0.751 ; 0.761$ ). The obtained data also show a clear relationship between quality of work and ISD of preparatory type $\left(\rho^{s}\right.$ $=0.445$ ); in the case of people with an ISW executive type, this was not found.

5. As the intercorrelations matrix shows, there is a relationship between intellectual readiness for action and ISW. Thus, a clear level of correlation was found between the formation of ISW, the correspondence of the used work methods to the reference and mental activity generalization $\left(\rho^{\mathrm{s}}=0.495 ; 0.544\right)$, its independence $\left(\rho^{\mathrm{s}}=0.514 ;-0.435\right)$. Awareness and resilience of mental activity also correlate with ISW in all indicators, but at a low level.

6. The presence of different level correlation is also revealed within the intellectual readiness limits between separate mental activity qualities. At a high level, the generalization and awareness of mental activity are related $\left(\rho^{s}=0.761\right)$; to a lesser extent generalization with independence $\left(\rho^{\mathrm{s}}=0.28\right)$. There is a small connection between awareness and independence $\left(\rho^{\mathrm{s}}=0.366\right)$, independence and resilience $\left(\rho^{\mathrm{s}}=0.376\right)$.

7. There is no significant relationship between action indicators - work tasks time characteristics and quality (including correctness, completeness).

\section{Discussion}

The research results of studying the psychological readiness for the work of design engineers in the general and special abilities theory context, the theoretical position on the need to take into account the general and individual typological mental subject's development, suggest that the design engineers' success with intellectual readiness for activity and its individual style. According to the study, the importance of getting a professional intellectual readiness for work - the formation of mental activity qualities system, which ensure the successful work tasks completion, namely its generalization, awareness, independence, resilience.

The top place in the system of these qualities belongs to the mental activity generalization - the ability to highlight in the conditions of the most important, which provides the definition of the optimal way of working. The formation of other subject's mind qualities in solving labor problems is an important prerequisite for generalizing the thinking of the employee in the process of choosing the optimal way to perform production tasks. The mental activity generalization, as the study found, is largely related to ISW, the importance of which increases in terms of adaptation of its temperamental specificities to activity, as it is a stable system of its ways to ensure the best work tasks performance taking into account subjective and objective working conditions. The ability to generalize affects the characteristics of ISW - its formation (certainty) and compliance with the reference sequence of labor operations. Thus, it was found that the core of psychological 
readiness for professional activity, the organizing factor in the unity of intellectual readiness and ISW, which ensure the work effectiveness, is the mental activity generalization. Similar results on different aspects of the research subject, conducted on different samples, built on different theoretical principles, were obtained by Zeier; Nosatov; Liashko; Bobrychenko; Maslakov, et al .; Sergeeva, et al.; Sokurenko, Shvets, \& Uvarov; Voloshenko, Dzhezhik, \& Azarkina [13-14].

\section{Conclusions}

Theoretical and empirical research aimed at studying the psychological readiness for the design engineers' work as a prerequisite for its effectiveness, conducted in the context of the general and special abilities theory, the need to take into account the general and individual-typological mental development of the subject, allowed the following general conclusions. The most important psychological readiness components for design engineers' professional activity are 1) intellectual readiness - a system readiness of formed mental qualities (generalization, awareness, independence, resilience), which provides a high level of assimilation and work tasks performance; 2) individual style of activity - its formation (certainty), type (preparatory or executive) and compliance with the reference execution method.

These components of psychological readiness are interrelated, and the organizing factor in their unity, the unity of their specific elements and their manifestation indicators, is the mental activity generalization, which provides the subject's ability to identify and use the best way to solve professional problems. The conclusion about the need for professionals to form these psychological readiness components is based on the results of the study, which show:

1) The presence of a correlation between intellectual readiness (generalization, awareness, independence, resilience, as qualities of mental activity) and work efficiency, and first of all in terms of time; intellectual quality has little effect on the work results quality.

2) The work efficiency (both in terms of quality and time) is largely affected by the individual style of the employee - his formation (certainty), compliance with the methods used to perform tasks reference, its type. At the same time, the types of individual activity style are differently related to the labor efficiency indicators: the preparatory type provides mainly a high level quality, the executive - high speed.

3) There is no correlation between the quality and time of professional tasks, as work efficiency indicators, which is important.

4) With the intellectual readiness to work, and above all with the generalization of the mind, at an expressive level is associated with the individual style of activity - its formation and compliance with the methods used to reference.

\section{References}

1. O. Khokhlina, L. Pomytkina, L. Yakovytska, O. Lych, D. Khokhlin, E3S Web of Conferences 210, 22041 (2020) doi: https://doi.org/10.1051/e3sconf/202021022041

2. V.M. Synov, O.P. Khokhlina, Aktualni pytannia korektsiinoi osvity 16(1), 230 (2020) doi: 10.32626/2413-2578.2020-16.230-244

3. I.M. Herrera, C.C. Barrientos, Revista Inclusions 6, 48 (2019)

4. R. Micallef, I. Huet, R. Kayyali, Pharmacy Education 20(1), 103 (2020)

5. R.S. Nagovitsyn, A.Y. Osipov, M.D. Kudryavtsev, K.K. Markov, A.N. Savchuk, L.V. 
Zakharova, I.I. Orlova, Amazonia Investiga 9(26), 341 (2020)

6. V.N. Petrova, N.V. Kozlova, Zhurnal - Siberian Journal of Psychology 70, 59 (2018) doi: $10.17223 / 17267080 / 70 / 5$

7. O. Khokhlina, L. Pomytkina, O. Lych, S. Gorbenko, A. Kazak, VIII International Scientific Conference Transport of Siberia. IOP Conference Series: Materials Science and Engineering 918 (2020) doi:10.1088/1757-899X/918/1/012175

8. E. Luzik, O. Akmaldinova, L. Tereminko, Advanced Education 13, 103 (2019) doi: 10.20535/2410-8286.185230

9. M. Pakhmutova, S. Bakhtina, S. Andreeva, T. Golovanova, 4th International Conference on Education (Dubai, 2017)

10. E. Ponomarenko, E. Krylov, K. Somova, $14^{\text {th }}$ International Technology, Education and development conference (Inted 2020) (Valencia, 2020)

11. V. Tolochek, Psikhologicheskii zhurnal 40(4), 57 (2019) doi: $10.31857 / \mathrm{S} 020595920005470-3$

12. O.M. Topuzov, O.V. Malykhin, T.M. Yarmolchuk, Information Technologies and Learning Tools 77(3), 205 (2020) doi: 10.33407/itlt.v77i3.3351

13. M.G. Sergeeva, A.V. Serebrennikova, N.G. Bondarenko, E.S. Getmanova, N.V. Klimovskikh, V.V. Yanckovsckaya, M.M. Asil'derova, Amazonia Investiga 8(18), 425 (2019)

14. V. Sokurenko, D. Shvets, V. Uvarov, Science and Education 3, 85 (2018) doi: 10.24195/2414-4665-2018-3-11 